Mr. T. Stevens described the development of electricity supply in the rural districts of Sweden, Denmark and Norway. Sweden is divided into fifteen areas for the supply of electricity and in most of these the State gives the supply, the remainder being in general owned by a municipality. In the cooperative distribution associations in Sweden, consumers have to hold shares proportional to the acreage of their farms or the number of rooms in their dwelling houses. A certain length of cable is allowed free of charge. When only small supplies are taken, the tariff is greater. Denmark exports to southern Sweden steam-electric power at the times when the water supply is insufficient, and Sweden reciprocates when necessary. In recent years the supply from Sweden has increased from 20 to 90 million kilowatt hours a year. Sweden has 2,387 hydro-electric plants. There are three submarine power lines connecting the two countries.

\section{Phosphates in Sugar Fermentation}

IN his second Liversidge Research Lecture before the Royal Society of New South Wales, Prof. W. J. Young discussed the "Functions of Phosphates in Fermentations of Sugar". Although the production of alcoholic liquors by the fermentation of sugar is older than recorded history, it was only in 1837 that the suggestion was made that the change is due to the living organism yeast. The final proof of this was the work of Pasteur, who showed that the conversion of sugar into aleohol and carbonic acid is a physiological action of the yeast cell. Later on, Buchner discovered that the active principle, or enzyme as it is now called, can be separated from the living cell and will still carry on the action after such separation. Further work has shown that fermentation is a series of chemical reactions in which phosphoric acid plays a part, and during the process compounds between the sugar and phosphoric acid, termed hexosephosphates, are formed. Phosphates play a similar rôle in other biological processes in which sugars are decomposed to simpler com. pounds, as, for example, in the animal during muscular activity. During muscular work the animal uses up carbohydrate as a source of energy and this is changed to lactic acid, a process which requires no oxygen. Thus an animal can do a certain amount of work without requiring oxygen, as, for example, in a short sprint race. Oxygen is required later on to remove the lactic acid, hence one goes on panting after the effort is over. Fermentation in yeast and lactic acid production in the animal are thus similar changes, the sugar being decomposed through the same intermediate compounds to alcohol and carbonic acid in the former, and to lactic acid in the latter, and for both phosphates are necessary, and the same sugar phosphates are produced.

Work of the National Institute of Industrial Psychology

THE Human Factor, 7, No. 12, presents the thirteenth annual report on the work of the National Institute of Industrial Psychology. The wide range of subjects dealt with by the Institute is very striking. The report gives brief indications of the work that has been done in factories, school buildings, retail stores, offices and even gold mines and tea and rubber plantations. The underlying problems of lay-out, 'processing' and personnel, etc., appear to have a certain similarity despite the diverse environments in which they are found. In the Research Section of the report, several interesting investigations are worthy of note. Mr. Harding's work on rhythm in occupational movements has thrown open new possibilities in relation to training schemes and the elimination of fluctuations in the speed of work in various occupations : its application to industry in general may be expected to produce far-reaching results. The nature and measurement of the mental abilities involved in factory assembly operations has been studied, and a colour-discrimination test is now ready for use. In addition, various occupational analyses have been undertaken, and the work on vocational and educational guidance has been maintained and extended.

\section{Uses of Rubber in the Home}

WE have received an interesting and wellillustrated reprint from the Furnishing Trades Organiser on "Rubber Flooring and Furnishings". Rubber flooring has been improved both as regards quality and design and the price has come down substantially. The latest type of sponge upholstery is made direct from rubber latex. It is moulded in one piece and obviates the necessity for built-up construction. Sofas, chairs, mattresses and loose cushions are now made of rubber and are stated to be practically everlasting. Lists of companies manufacturing these products are given in the reprint, which is issued by the Rubber Growers' Association (Inc.), 2, 3 and 4 Idol Lane, Eastcheap, London, E.C.3.

\section{Coloration of Fossil Bones}

In the September number of Revue Scientifique occurs the last of a series of articles upon the coloration of bones which have been for longer or shorter periods buried in the ground. In the present article, L. Franchet deals with the effects upon bones of the boiling of a corpse, and the various colour changes due to incineration. The articles, in which the author discusses experiments he has made to check the effects which occur naturally, should be of value especially to archæologists and prehistorians, particularly in warning against rash deductions regarding the age of buried bones, derived solely from the condition of the bones.

\section{Crystal Structure Models}

Is the October issue of the Review of Scientific Instruments, Mr. G. Glockler, of the University of Minnesota, describes a convenient form of model of crystal structure. The atoms are represented by black, white or coloured dots on vertical sheets of 'Cellophane', which are hinged along their bottom edges to a thin sheet of wood or cardboard and can be folded down for packing. When so folded, each model is about the size of a volume of Nature. 